\title{
Erratum to: Quality of patient information on the internet for the treatment of anal fistula and anal fissure
}

\author{
F. Scott $\cdot$ A. Sehgal $\cdot$ H. M. Joshi $\cdot$ T. M. Yeung $\cdot$ \\ M. P. Gosselink
}

Published online: 20 November 2014

(C) Springer-Verlag Italia Srl 2014

\section{Erratum to: Tech Coloproctol \\ DOI 10.1007/s10151-014-1222-0}

In the original publication of the article, the family name of the second author was wrongly spelled as A. Seghal. It should be replaced by A. Sehgal.

The online version of the original article can be found under doi:10.1007/s10151-014-1222-0.

F. Scott $\cdot$ A. Sehgal

Oxford University Medical School, Oxford, UK

H. M. Joshi $(\bowtie) \cdot$ T. M. Yeung · M. P. Gosselink

Nuffield Department of Surgery, Oxford University Hospitals

Trust, Oxford, UK

e-mail: heman.joshi@seh.ox.ac.uk

M. P. Gosselink

e-mail: mpgosselink@gmail.com 